\title{
Finland is following the trend—sperm quality in Finnish men
}

\author{
Helena E Virtanen, Sergey Sadov, Matti Vierula and Jorma Toppari
}

Asian Journal of Andrology (2013) 15, 162-164; doi:10.1038/aja.2012.142; published online 14 January 2013

$\mathrm{F}$ innish men have had a reputation for semen studies comparing Finnish men with other Europeans. However, those studies also showed that sperm concentrations of young men from the general population were only two-thirds of those of fertile men. Longitudinal follow-up of semen quality in young Finnish men showed a significant decline during 1998-2006, suggesting that Finland is following the global trend of impaired male reproductive health.

In 1992, Carlsen et al. ${ }^{1}$ reported that mean sperm concentrations had decreased from $113 \times 10^{6}$ to $66 \times 10^{6} \mathrm{ml}^{-1}$ between the years 1940 and 1990 (Figure 1). That systematic review included 61 studies from different countries, ${ }^{1}$ including one study from Finland. ${ }^{2}$ In the analysis, only studies of men with known fertility or studies of unselected men were included. The results of declining sperm concentrations were supported by a reanalysis of the studies (56 studies included) by Swan et al. ${ }^{3}$ and by an extended analysis by Swan et al., ${ }^{4}$ which included altogether 101 studies published between the years 1934 and 1996. In these two latter analyses, a decline in sperm concentration in the United States/North America and in Europe was found, but not in non-western countries, where too few studies were available for a robust analysis. Significant inter- and intraregional differences in sperm concentrations were also observed. ${ }^{3}$ The World Health Organization-defined lower limit for normal sperm concentration has recently declined from 20 to 15 million $\mathrm{ml}^{-15}$, while in the past limit was 60 million $\mathrm{ml}^{-1}$. The aim of this paper is to present an updated review on possible temporal changes in sperm concentrations in Finland.

Departments of Physiology and Paediatrics, University of Turku, Turku, Fl-20520, Finland

Correspondence: Dr J Toppari (jorma.toppari@utu.fi) Received: 3 October 2012; Revised: 12 November 2012; Accepted: 13 November 2012; Published online: 14 January 2013

\section{FINNISH STUDIES}

Older Finnish studies evaluated sperm counts in men of infertile couples. Johansson and Vehaskari $^{7-9}$ evaluated semen quality of men in sterile marriages and Leikkola ${ }^{6}$ investigated semen quality of men from childless marriages. Although these studies represented infertile couples, the sperm concentrations were high in masturbation samples (mean 117 million $\mathrm{ml}^{-1}$ ) and in coitus interruptus samples (mean 146 million $\mathrm{ml}^{-1}$ ). ${ }^{6}$ In a previous review from Finland, ${ }^{10}$ only studies on men with proven fertility and studies on normal men with unknown fertility were included: Takala ${ }^{11}$ evaluated semen quality in 189 fathers of children with congenital malformations, but only total sperm count was reported, and in the previous review, concentration was calculated from an approximated semen volume of $3.4 \mathrm{ml}^{10}$ Nikkanen $^{2}$ studied the effects of vasectomy on the properties of the semen in 21 men. Suominen et al. ${ }^{12}$ studied semen of 56 men whose partners were pregnant or who had recently delivered. Saaranen et al. ${ }^{13}$ evaluated semen quality of 144 men representing couples who were trying to conceive and who had no history of infertility. Iirola and $\mathrm{Niemi}^{14}$ reported sperm concentrations of 300 semen donor candidates and Wichmann ${ }^{15}$ studied semen quality of 139 men with proven fertility. In the review of the studies mentioned above and published in 1993, Suominen and Vierula ${ }^{10}$ found no evidence of a significant decrease in sperm concentrations in Finnish men between the years 1958 and 1992. The sperm concentrations of these studies can be seen in Figure 1.

After the review, Vierula et al. ${ }^{16}$ reported sperm counts of 238 healthy men from couples trying to conceive during 1984-1986. Most of the men came from the city of Kuopio and they were recruited via newspaper advertisements. The mean sperm concentration in normal healthy men with unknown fertility was high, $133.9 \times 10^{6} \mathrm{ml}^{-1} \cdot{ }^{16}$ Vierula et al. ${ }^{16}$ evaluated also possible changes with time in sperm concentrations: no significant change in sperm concentration (82-85 million $\mathrm{ml}^{-1}$ ) or total sperm count (345-325 million per ejaculate) during 1967-1994 was observed when evaluating samples of 5253 men from infertile couples from the Turku area.

Like men from infertile couples, neither semen donors and donor candidates nor fertile men represent a random sample of the male population. ${ }^{16}$ However, military conscripts or unselected young men may be considered representative of the general population of young men. ${ }^{17}$ The most recent studies on semen quality in Finland included 18- to 19-year-old Finnish men from the general population from Turku area representing birth cohorts 1979-1981, 1982-1983 and $1987 .{ }^{17,18}$ Young men in the most recent birth cohort showed significantly lower sperm concentrations and total sperm counts than men in the earlier birth cohorts. ${ }^{18}$

Figure 1 shows the mean sperm concentrations in Finnish studies on fertile men or normal men with unknown fertility. Similar inclusion criteria and study methods were used in the Finnish studies on young men. ${ }^{17,18}$ Whereas in older Finnish studies there were differences in inclusion criteria, semen collection (masturbation or coitus interruptus) and in abstinence time, and the men were older (if their age was mentioned). These factors complicate comparison of the older and more recent Finnish studies.

\section{FINLAND VS. OTHER COUNTRIES}

Carlsen et al. ${ }^{1}$ noted in their review that Danish men seemed to have lower sperm concentrations than Finnish men. In the year 2000, Jensen et al. ${ }^{19}$ compared semen quality of Finnish ${ }^{16}$ and Danish men trying to impregnate their partners. Finnish men without proven fertility had significantly higher sperm concentrations (after controlling for confounding factors) than Danish men without proven fertility, and mean levels were 126.8 and 68.5 million $\mathrm{ml}^{-1}$, respectively. ${ }^{19}$ How- 


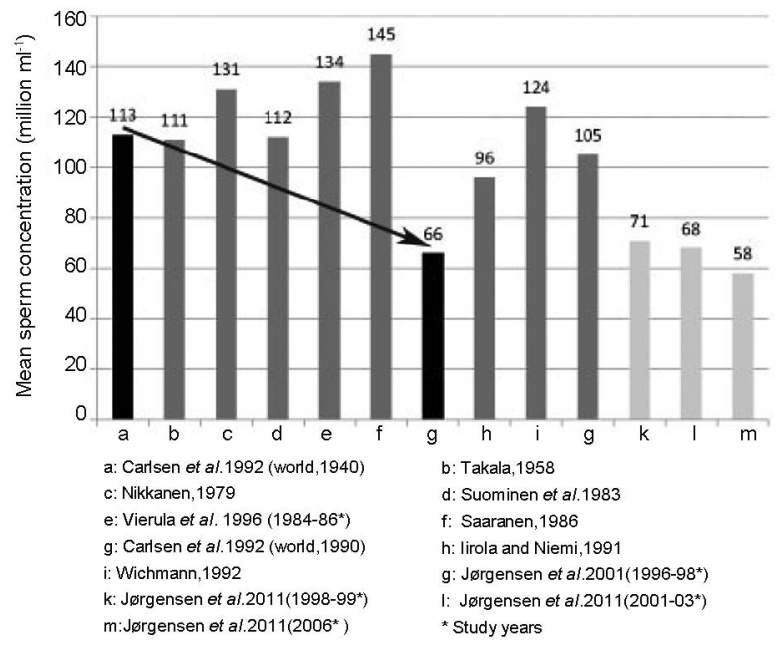

Figure 1 Mean sperm concentration: world trend (according to Carlsen et al. 1992: ${ }^{1}$ black bars), Finnish studies on fertile men or normal men with unknown fertility (dark grey bars) and on unselected 19-year-old young men (light grey bars). Study periods in parenthesis. (See the text for references). ever, differences in recruitment period and methods may explain some of the observed between country difference. ${ }^{19}$ Jørgensen et al..$^{20}$ studied male partners of pregnant women in Copenhagen (Denmark), Turku (Finland), Edinburgh (Scotland) and Paris (France) in a cross-sectional study by using co-ordinated standardized study procedures and focusing on possible geographical differences in semen quality. Men from Turku had higher sperm concentrations than men from the other three European cities, whereas the lowest sperm concentrations were observed in men from Copenhagen $^{20}$ (Figure 2). However, infertile men were not included in studies of partners of pregnant women, and subfertile men are likely to be underrepresented in such studies, ${ }^{20}$ and thus, as discussed above, studies on young men are likely to reflect better the situation in the population.
Jørgensen et al. ${ }^{17}$ investigated semen quality in young men not selected for fertility or semen quality in Copenhagen, Oslo (Norway), Turku and Tartu (Estonia) in a co-ordinated cross-sectional study. ${ }^{17}$ Finnish young men were observed to have significantly higher sperm concentrations than Danish and Norwegian young men, after adjustment for confounding factors, but no significant difference in sperm concentration from that of young men from Tartu was observed (Figure 3). ${ }^{17}$ Thus, the previously described Danish-Finnish difference in sperm concentrations ${ }^{20}$ was confirmed by the study on young men.

Punab et al. ${ }^{21}$ also evaluated semen quality of Estonian and Lithuanian military conscripts. They reported that although the men in this study were somewhat older than the men in the study by Jørgensen et al., ${ }^{17}$ the

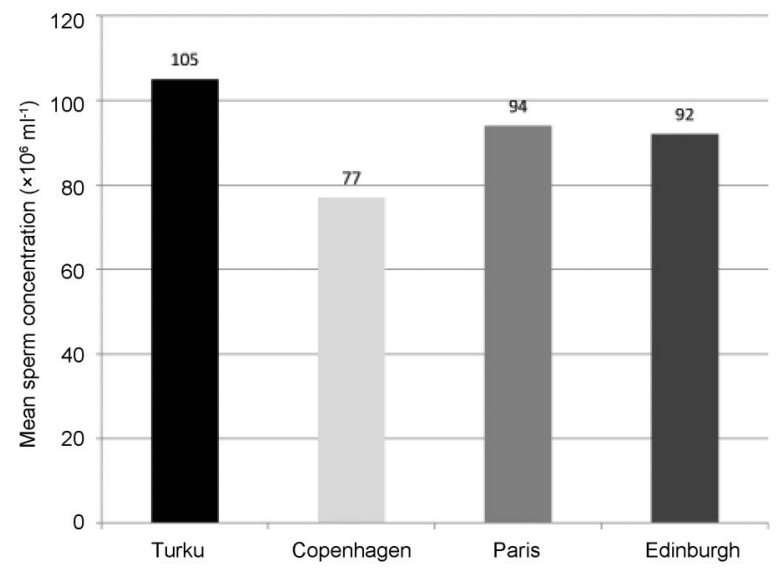

Figure 2 Mean sperm concentrations of fertile men from four cities in Europe (Based on Jørgensen et al. ${ }^{20}$ ). median sperm concentrations, adjusted to the Danish laboratory level (according to quality control results) and abstinence time, were 67 and 55 million $\mathrm{ml}^{-1}$ in the Estonian city Tartu and in the Lithuanian city Kaunas, respectively, ${ }^{21}$ and thus they seem to be higher than reported previously in Finnish $\operatorname{men}^{17}$ (Figure 3). Tsarev et al. ${ }^{22}$ studied semen quality in Latvian military conscripts, and they found that the median sperm concentration was 63 million $\mathrm{ml}^{-1}$. According to Tsarev et al., this was similar to sperm concentrations in Finland, Lithuania and Estonia. ${ }^{17,21,22}$ However, no adjustment for a reference laboratory level was made, which complicates direct comparison. More recently, during the years 2003-2005, Paasch et al. ${ }^{23}$ studied young men from eastern and western Germany (Leipzig and Hamburg) by using the same protocol as in the above mentioned studies on young men. ${ }^{17}$ Adjusted median sperm concentrations were 46 and 42 million $\mathrm{ml}^{-1}$, respectively, in Hamburg and Leipzig, ${ }^{23}$ which seem to be lower than the comparable levels reported from Finland in $2002^{17}$ (Figure 3).

\section{POSSIBLE CAUSES FOR DECLINE IN SEMEN QUALITY}

Causes for adverse trends and regional differences in sperm concentration are not known. Genetic background may explain some of the regional differences, but the trends point to a significant environmental contribution. Currently we do not know the environmental effectors. On the basis of biological knowledge, endocrine disrupters affecting testicular development can be considered putative culprits. ${ }^{24}$ While this is challenging to prove in human epidemiology, owing to complex exposures to thousands of chemicals, we need to stay alert by continuing semen quality studies to protect male reproductive health.

\section{CONSEQUENCES OF SEMEN QUALITY DETERIORATION}

In the latest study on young Finnish men, ${ }^{18}$ an increasing tendency of the percentage of men having sperm concentrations below 40 million $\mathrm{ml}^{-1}$ was observed. In the latest birth cohort, $43 \%$ of men had sperm concentration below the limit of 40 million $\mathrm{ml}^{-1},{ }^{18}$ which has been associated with decreased fertility via increasing time to pregnancy. ${ }^{25}$ In a more recent study, below the sperm concentration of 55 million $\mathrm{ml}^{-1}$, time to pregnancy was observed to increase with decreasing sperm concentrations. ${ }^{26}$ This suggests that an increasing percentage of 


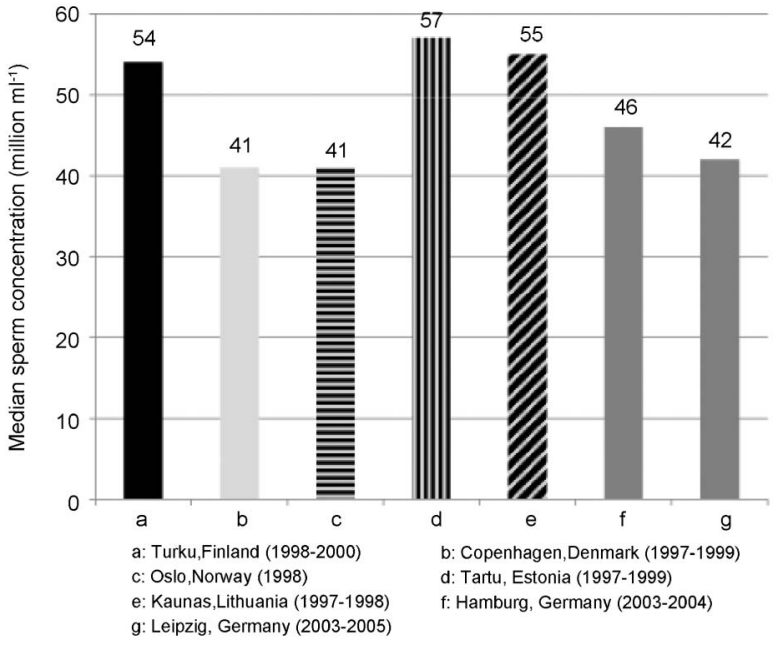

Figure 3 Adjusted (to the Danish laboratory level and to a period of ejaculation abstinence of at least $96 \mathrm{~h}$. Recent fever was also accounted for in Paasch et al. ${ }^{23}$ ) median sperm concentrations of young men from six European countries. Study periods in parenthesis. (Based on Jørgensen et al., ${ }^{17}$ Punab et al. ${ }^{21}$ and Paasch et al. ${ }^{23}$ ).

Finnish men may suffer of reduced fertility in the future. $^{18}$ In Denmark, Norway and Germany also, a notable proportion of young men have semen concentrations below 40 or 55 million $\mathrm{ml}^{-1} \cdot 17,23$

Semen quality in young Finnish men is not good and causes concern for andrologists. An increasing need for assisted reproduction techniques, such as sperm microinjection and insemination by donor sperm has been reported in Finland over the last few years. ${ }^{27}$

\section{CONCLUSION}

Finnish men had high sperm concentrations in studies published during the last decades. However, according to most recent studies on young men published in 2011, sperm concentrations have declined in Finland, unrelated to lifestyle, age or abstinence time. Follow-up of new cohorts of young Finnish men is needed to study whether such a trend will continue.

\section{COMPETING FINANCIAL INTERESTS}

All authors declare that there are no competing financial interests.

\section{ACKNOWLEDGMENTS}

The work was supported by the Academy of Finland, the Turku University Hospital, the Sigrid
Jusélius Foundation, the European Commission (QLK4-CT-1999-01422, QLK4-CT-2001-00269, QLK4-2002-00603 and FP7/2008-2012: DEER 212844) and the Danish Council for Strategic Research and the Danish Agency for Science, Technology and Innovation (09-067180).

1 Carlsen E, Giwercman A, Keiding N, Skakkebaek NE. Evidence for decreasing quality of semen during past 50 years. BMJ 1992; 305: 609-13.

2 Nikkanen V. The effects of vasectomy on viscosity, $\mathrm{pH}$ and volume of semen in man. Andrologia 1979; 11: 123-5.

3 Swan SH, Elkin EP, Fenster L. Have sperm densities declined? A reanalysis of global trend data. Environ Health Perspect 1997; 105: 1228-32.

4 Swan SH, Elkin EP, Fenster L. The question of declining sperm density revisited: an analysis of 101 studies published 1934-1996. Environ Health Perspect 2000; 108: 961-6.

5 World Health Organization. WHO laboratory manual for the examination and processing of human semen. 5th ed. Geneva: WHO Press; 2010.

6 Leikkola A. Seminal fluids, composition in barren marriages. Acta Obstet Gynecol Scand Suppl 1955; 34: 1-105.

7 Johansson CJ. Classification of semen and the relationship between semen and testicles of men in sterile marriages. Ann Chir Gynaecol Fenn Suppl 1949; 38: 122-37.

8 Vehaskari A. On Sterility in Finnish Women with Special Reference to its Causes and Prognosis. Helsinki: University of Helsinki; 1948. p123.
9 Johansson CJ. Fertility in men in barren marriages. Acta Obstet Gynec Scand 1950; 20: 252-8.

10 Suominen J, Vierula M. Semen quality of Finnish men. BMJ 1993; 306: 1579.

11 Takala ME. Paternal and Maternal Factors in the Etiology of Congenital Malformations. A Study of 241 Defect-bearing Families. Turku: University of Turku; 1958. p168.

12 Suominen J, Grönroos M, Terho P, Wichmann L. Chronic prostatitis, chlamydia trachomatis and infertility. Int J Androl 1983; 6: 405-13.

13 Saaranen M, Vierula M, Saarikoski S. Semen quality in men of infertile couples and in men of reproductive age. In: Aravantinos D, Creatsas G, editors. $V$ World Congress on Human Reproduction. Athens: Hellenic Society on the Study of Reproduction; 1986. p298-300.

14 lirola T, Niemi M. Suomalainen spermanluovuttaja. Duodecim 1991; 107: 1069-74.

15 Wichmann $L$. The value of semen analysis in predicting pregnancy. Vammala: University of Tampere; 1992. p100.

16 Vierula M, Niemi M, Keiski A, Saaranen M, Saarikoski $S$ et al. High and unchanged sperm counts of Finnish men. Int J Androl 1996; 19: 11-7.

17 Jørgensen N, Carlsen E, Nermoen I, Punab M, Suominen $\mathrm{J}$ et al. East-West gradient in semen quality in the Nordic-Baltic area: a study of men from the general population in Denmark, Norway, Estonia and Finland. Hum Reprod 2002; 17: 2199-208.

18 Jorgensen $N$, Vierula $M$, Jacobsen R, Pukkala E, Perheentupa $A$ et al. Recent adverse trends in semen quality and testis cancer incidence among Finnish men. Int J Androl 2011; 34: e37-48.

19 Jensen TK, Vierula M, Hjollund NH, Saaranen M, Scheike $T$ et al. Semen quality among Danish and Finnish men attempting to conceive. The Danish First Pregnancy Planner Study Team. Eur J Endocrinol 2000; 142: 47-52.

20 Jørgensen N, Andersen AG, Eustache F, Irvine DS, Suominen $\mathrm{J}$ et al. Regional differences in semen quality in Europe. Hum Reprod 2001; 16: 1012-9.

21 Punab M, Zilaitiene B, Jørgensen N, Horte A, Matulevicius $\checkmark$ et al. Regional differences in semen qualities in the Baltic region. Int J Androl 2002; 25: 243-52.

22 Tsarev I, Gagonin V, Giwercman A, Erenpreiss J. Sperm concentration in Latvian military conscripts as compared with other countries in the NordicBaltic area. Int J Androl 2005; 28: 208-14.

23 Paasch U, Salzbrunn A, Glander HJ, Plambeck K, Salzbrunn $\mathrm{H}$ et al. Semen quality in sub-fertile range for a significant proportion of young men from the general German population: a co-ordinated, controlled study of 791 men from Hamburg and Leipzig. Int J Androl 2008; 31: 93-102.

24 Sharpe RM. Sperm counts and fertility in men: a rocky road ahead. Science \& Society Series on Sex and Science. EMBO Rep 2012; 13: 398-403.

25 Bonde JP, Ernst E, Jensen TK, Hjollund NH, Kolstad H et al. Relation between semen quality and fertility: a population-based study of 430 first-pregnancy planners. Lancet 1998; 352: 1172-7.

26 Slama R, Eustache F, Ducot B, Jensen TK, Jørgensen $\mathrm{N}$ et al. Time to pregnancy and semen parameters: a cross-sectional study among fertile couples from four European cities. Hum Reprod 2002; 17: 503-15.

27 Heino A, Gissler M. Assisted fertility treatments 2010-2011. National Institute for Health and Welfare, Helsinki, Finland, 2012. Statistical report. 